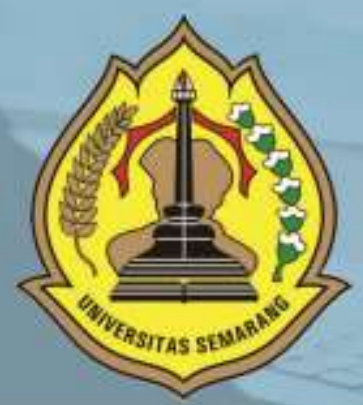

PENGARUH WORK FAMILY CONFLICT, STRES KERJA DAN KEPEMIMPINAN TERHADAP TURNOVER INTENTION KARYAWAN (STUDI PADA SELURUH KARYAWAN BAGIAN PLANNING PRODUCTION AND INVENTORY CONTROL PT. PARKLAND WORLD INDONESIA JEPARA

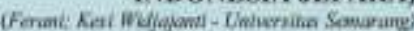

STUDI SOFT SKILL LULUSAN PENDIDIKAN KEJURUAN DI TEMPAT KERJA

Whort-Chiversikio Semorang

ANALISIS IINGKUNGAN INTERNAL DAN EKSTERNAL, PADA UKM PREMIUM PLUS LAUNDRY CABANG MULAWARMAN SEMARANG

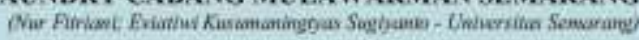

FAKTOR-FAKTOR YANG MEMPENGARUHI PERTIMBANGAN TINGKAT MATERIALITAS AUDIT

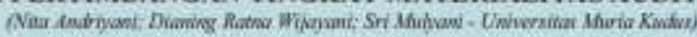

MANAJEMEN LABA DAN FAKTOR-FAKTOR YANG MEMPENGARUHINYA (STUDI EMPIRIS PADA PERUSAHAN MANUFAKTUR DI BEI)

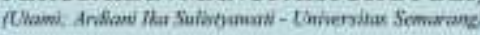

PENDAPATAN ASLI DAERAH, DANA PERIMBANGAN, DAN SISA LEBIH PEMBIAYAAN ANGGARAN TERHADAP PENGALOKASIAN BELANJA MODAL: STUDI PADA KABUPATEN/KOTA DI PROVINSI JAWA TENGAH

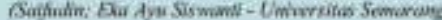

PERSEPSI PENGGUNA JASA TRANS JATENG TERHADAP KUALITAS PELAYANAN ANGKUTAN AGLOMERASI PERKOTAAN TRANS

JATENG

(Studi Kasus Trans Jateng Koridor I Semarang (Tawang) - Bawen)

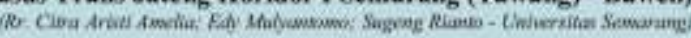

WORTHLESSNESS IS A POWER: MENGAPA ORANG BERSEDIA MENARUH UANG DI APLIKASI GO-PAY

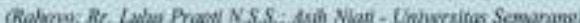

ANALISIS PENGARUH KUALITAS PRODUK, PERSEPSI HARGA, DAN PROMOSI TERHADAP KEPUTUSAN PEMBEIIAN WELLBLUE AL KALINE WATER PITCHER

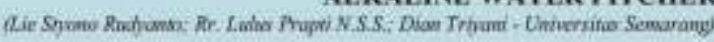

STRATEGI PEMASARAN UNTUK MENINGKATKAN VOLUME PENJUALAN (STUDI KASUS PADA SHOFA CATERING)

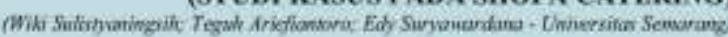

PENGARUH CITRA MEREK, PERSEPSI HARGA, DAN KUALITAS PRODUK TERHADAP KEPUTUSAN PEMBELIAN SEPATU OLAH RAGA MEREK ADIDAS

(Studi di Kota Semarang)

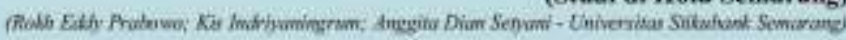

PENGARUH KEMUDAHAN TERHADAP KEPUTUSAN MENGGUNAKAN E-BANKING PADA BNI 46 KC KARANGAYU SEMARANG DENGAN MINAT NASABAH DAN KEPERCAYAAN SEBAGAI VARIABEL. MEDIASI

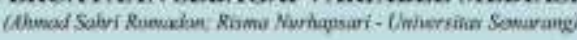

PENELITLAN KEBERLANGSUNGAN USAHA ARDANI INDONESIA SEBAGAI UMKM BERBASIS INDUSTRI KREATIF

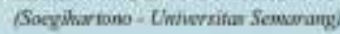

STRATEGI PELAYANAN BUS RAPID TRANSIT (BRT) TRANS SEMARANG

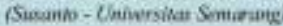

ANALISIS PENGARUH KEPEMIMPINAN, STRES KERJA, DAN LINGKUNGAN KERJA TERHADAP KINERJA KARYAWAN BAGIAN PRODUKSI SEWING PT. SAMWON BUSANA INDONESIA SEMARANG

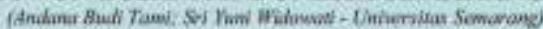




\section{DESKRIPSI}

Majalah IImiah Solusi Mengkaji

Masalah-Masalah Sosial,

Ekonomi dan Bisnis

\section{KETERANGAN TERBIT}

Terbit Pertama Kali Juli 2002

dan SelanjutnyaTerbit Tiga Bulan

Sekali (Januari, April, Juli dan

Oktober)

\section{PENERBIT}

Fakultas Ekonomi USM

\section{ALAMAT PENERBIT}

JL. Soekarno Hatta Semarang

Telp. 024-6702757 Fax. 024-6702272

\section{PENGELOLA}

Editor in Chief : Yohanes Suhardjo, SE, M.Si., Ak, CA Vice Editor Chief : Sugeng Rianto, SE, MM

Managing Editor: Edy Suryawardana, SE, MM

Secretary of Managing Editor : Asih Niati, SE, MM

Administration \& Circulation :

Citra Rizkiana, SE, MM

Layout \& Typesetting : M Burhan Hanif S.Kom, M.Kom

Board of Editors:

1. Prof. Dr. Ir. Kesi Widjajanti, SE, MM (USM)

2. Prof. Drs. Mohammad Nasir, Msi, Ph.D, AK. (USM)

3. Prof. Supramono SE, MBA, DBA (UKSW)

4. Prof. Drs. H. Imam Ghozali, M.Com, Akt, PhD (UNDIP)

5. Prof. Dr. Agus Suroso, MS (UNSOED)

6. Prof. Dr. Widodo, SE, M.Si (UNISSULA)

7. Prof. Dr. Dra. Sulastri, ME, M.Kom (UNSRI)

8. Dr. Ardiani Ika S, SE, MM, Ak, CA, CPA (USM)

\section{KATA PENGANTAR}

Sungguh merupakan kebahagiaan tersendiri bagi kami, takala kami dapat hadir rutin setiap tiga bulan sekali untuk saling bertukar pikiran mengenai hal-hal baru dibidang sosial, ekonomi dan bisnis.

Pada kesempatan ini penerbit menyampaikan terima kasih kepada semua pihak yang telah mengirimkan artikel-artikelnya. Penerbit akan membuka kesempatan seluas-luasnya bagi seluruh kalangan akademisi maupun praktisi baik dari dalam maupun luar Universitas Semarang untuk mempublikasikan karya ilmiahnya.

Penerbitan majalah ilmiah "SOLUSI" kali ini menghadirkan 15 (Lima Belas) artikel yang kami anggap layak untuk diterbitkan, dengan harapan dapat menjadi tambahan referensi bagi para pembaca dan menjadi sumbangan pengembangan persemaian khasanah pengetahuan dibidang sosial, ekonomi dan bisnis.

Akhir kata semoga majalah ilmiah "SOLUSI" dapat memberi manfaat yang sebesar-besarnya.

Hormat Kami 


\section{DAFTAR ISI}

PENGARUH WORK FAMILY CONFLICT, STRES KERJA DAN KEPEMIMPINAN TERHADAP TURNOVER INTENTION KARYAWAN (STUDI PADA SELURUH KARYAWAN BAGIAN PLANNING PRODUCTION AND INVENTORY CONTROL PT. PARKLAND WORLD INDONESIA JEPARA)

(Ferani; Kesi Widjajanti - Universitas Semarang)

STUDI SOFT SKILL LULUSAN PENDIDIKAN KEJURUAN DI TEMPAT KERJA

(Albert - Universitas Semarang)...

ANALISIS LINGKUNGAN INTERNAL DAN EKSTERNAL PADA UKM PREMIUM PLUS

LAUNDRY CABANG MULAWARMAN SEMARANG

(Nur Fitriani; Eviatiwi Kusumaningtyas Sugiyanto - Universitas Semarang)

FAKTOR-FAKTOR YANG MEMPENGARUHI PERTIMBANGAN TINGKAT

MATERIALITAS AUDIT

(Nita Andriyani; Dianing Ratna Wijayani; Sri Mulyani - Universitas Muria Kudus).

MANAJEMEN LABA DAN FAKTOR-FAKTOR YANG MEMPENGARUHINYA

(STUDI EMPIRIS PADA PERUSAHAN MANUFAKTUR DI BEI)

(Utami; Ardiani Ika Sulistyawati - Universitas Semarang)

PENDAPATAN ASLI DAERAH, DANA PERIMBANGAN, DAN SISA LEBIH PEMBIAYAAN ANGGARAN TERHADAP PENGALOKASIAN BELANJA MODAL: STUDI PADA

KABUPATEN/KOTA DI PROVINSI JAWA TENGAH

(Saifudin; Eka Ayu Siswanti - Universitas Semarang).

PERSEPSI PENGGUNA JASA TRANS JATENG TERHADAP KUALITAS PELAYANAN ANGKUTAN AGLOMERASI PERKOTAAN TRANS JATENG

(Studi Kasus Trans Jateng Koridor I Semarang (Tawang) - Bawen)

(Rr. Citra Aristi Amelia; Edy Mulyantomo; Sugeng Rianto - Universitas Semarang)

WORTHLESSNESS IS A POWER: MENGAPA ORANG BERSEDIA MENARUH UANG DI APLIKASI GO-PAY

(Rahoyo; Rr. Lulus Prapti N.S.S.; Asih Niati - Universitas Semarang).

ANALISIS PENGARUH KUALITAS PRODUK, PERSEPSI HARGA, DAN PROMOSI TERHADAP KEPUTUSAN PEMBELIAN WELLBLUE ALKALINE WATER PITCHER

STRATEGI PEMASARAN UNTUK MENINGKATKAN VOLUME PENJUALAN (STUDI KASUS PADA SHOFA CATERING)

(Wiki Sulistyaningsih; Teguh Ariefiantoro; Edy Suryawardana - Universitas Semarang)

PENGARUH CITRA MEREK, PERSEPSI HARGA, DAN KUALITAS PRODUK TERHADAP KEPUTUSAN PEMBELIAN SEPATU OLAH RAGA MEREK ADIDAS

(Studi di Kota Semarang)

(Rokh Eddy Prabowo; Kis Indriyaningrum; Anggita Dian Setyani - Universitas Stikubank Semarang) .121

PENGARUH KEMUDAHAN TERHADAP KEPUTUSAN MENGGUNAKAN E-BANKING PADA BNI 46 KC KARANGAYU SEMARANG DENGAN MINAT NASABAH DAN KEPERCAYAAN SEBAGAI VARIABEL MEDIASI

(Ahmad Sahri Romadon; Risma Nurhapsari - Universitas Semarang) 
PENELITIAN KEBERLANGSUNGAN USAHA ARDANI INDONESIA SEBAGAI UMKM BERBASIS INDUSTRI KREATIF

(Soegihartono - Universitas Semarang)

STRATEGI PELAYANAN BUS RAPID TRANSIT (BRT) TRANS SEMARANG

(Susanto - Universitas Semarang).....

ANALISIS PENGARUH KEPEMIMPINAN, STRES KERJA, DAN LINGKUNGAN KERJA TERHADAP KINERJA KARYAWAN BAGIAN PRODUKSI SEWING PT. SAMWON BUSANA INDONESIA SEMARANG

(Andana Budi Tami; Sri Yuni Widowati - Universitas Semarang). 


\title{
STRATEGI PELAYANAN BUS RAPID TRANSIT (BRT) TRANS SEMARANG
}

\author{
Susanto \\ Fakultas Ekonomi Universitas Semarang \\ Diterima: Agustus 2020, Disetujui: September 2020, Dipublikasikan: Oktober 2020
}

\begin{abstract}
This research was conducted on users of the Trans Semarang Bus Rapid Transit (BRT) transportation. The purpose of this research is (1) to analyze the attractiveness of Trans Semarang BRT users, (2) to find out the quality of Trans Semarang BRT services.

This study uses qualitative methods, using triangulation of data sources namely observation, interviews, and documentation. Informants research is based on the principle of appropriateness and adequacy. There are 6 basic principles of informants in this study.

The results of this study state that the factors that attract users to use the Trans Semarang BRT (Bus Rapid Transit) transportation are because Trans Semarang has affordable fares, provides comfort in the form of adequate facilities and guarantees safety on the bus such as separate seating for men male and female. In addition, the quality of its service is good with the presence of friendly and resolute officers in serving customers.
\end{abstract}

Keywords: Bus Rapid Transit (BRT), Attractiveness, Service Quality

ABSTRAK

Penelitian ini dilakukan pada pengguna angkutan BRT (Bus Rapid Transit) Trans Semarang. Tujuan penelitian ini adalah untuk mengetahui kualitas pelayanan BRT Trans Semarang.

Penelitian ini menggunakan metode kualitatif, dengan menggunakan triangulasi sumber yaitu observasi, wawancara, dokumentasi. Penelitian informan didasarkan pada prinsip kesesuaian (appropriateness) dan kecukupan (adequacy). Dasar prinsip informan didalam penelitian ini ada 6 orang.

Hasil penelitian ini menyatakan bahwa upayaa yang dilakukan oleh BRT Trans Semarang dalam memberikan pelayanan kepada pelanggan dianataranya yaitu penerapan tarif Trans Semarang yang terjangkau, memberikan kenyamanan berupa fasilitas-fasilitas yang memadai dan menjamin keamanan di dalam bis seperti terpisahnya tempat duduk laki-laki dan perempuan. Selain itu, kualitas pelayanan nya baik dengan adanya petugas yang ramah dan tegas dalam melayani pelanggan.

Kata Kunci: Daya tarik, Kualitas Pelayanan 


\section{PENDAHULUAN}

Semakin berkembangnya zaman, kini telah memberikan implikasi terhadap perubahan manusia. Sebagaimana yang terlihat bahwa setiap manusia senantiasa mengalami perubahan-perubahan. Perubahan tersebut pada awalnya masih tradisional berubah menjadi modern, hal ini disebabkan oleh adanya pembangunan dan berkembangnya transportasi.

Semarang merupakan salah satu kota besar yang ada di Indonesia, yang menjadi ibukota dari Provinsi Jawa Tengah. Sebagai pusat dari suatu provinsi, Semarang memiliki banyak potensi, baik dari sektor pariwisata, industri, dan pendidikan. Karena potensi yang dimiliki itu, Semarang juga memiliki tingkat kepadatan penduduk yang tinggi. Hal ini dapat memicu terjadinya beberapa masalah yang ada di Kota Semarang, salah satunya adalah kemacetan lalu lintas.

BRT (Bus Rapid Transit) Trans Semarang merupakan sebuah layanan angkutan massal berbasis Bus Rapid Transit (BRT). BRT (Bus Rapid Transit) Trans Semarang diresmikan oleh Pemerintah Kota Semarang pada 2 Mei 2009 bertepatan dengan hari jadi Kota Semarang yang ke- 462, yang dikelola oleh Badan Layanan Umum (BLU). Rahma et al (2014) mengajukan argumen nya bahwa jasa transportasi umum yang telah diselenggarakan oleh Pemerintah Kota Semarang diharapkan dapat mengatasi masalah kemacetan yang diakibatkan oleh cepatnya pertumbuhan kendaraan pribadi, serta diharapkan menjadi alat transportasi yang efektif dari segi waktu.

Berikut adalah data jumlah penumpang BRT (Bus Rapid Transit) Trans Semarang pada tahun 2010 sampai 2018, sebagai berikut :

Tabel 1.1

Data Jumlah Penumpang BRT (Bus Rapid Transit) Tahun 2010-2018

\begin{tabular}{|c|c|}
\hline Tahun & Jumlah Penumpang \\
\hline 2010 & 369.326 \\
\hline 2011 & 1.678 .542 \\
\hline 2012 & 1.960 .200 \\
\hline 2013 & 3.821 .145 \\
\hline 2014 & 5.832 .450 \\
\hline 2015 & 8.023 .869 \\
\hline 2016 & 7.725 .490 \\
\hline 2017 & 9.125 .472 \\
\hline 2018 & 10.210 .296 \\
\hline
\end{tabular}

Sumber : UPTD BLU BRT Trans Semarang 
Berdasarkan tabel 1.1 diatas, menunjukkan bahwa jumlah penumpang BRT (Bus Rapid Transit) Trans Semarang mengalami peningkatan selama tiga tahun terakhir. Pada tahun 2016 jumlah penumpang BRT (Bus Rapid Transit) Trans Semarang mengalami penurunan, tetapi di tahun berikutnya jumlah penumpang BRT (Bus Rapid Transit) Trans Semarang mengalami peningkatan kembali.

Berdasarkan latar belakang masalah yang telah diuraikan, dapat diketahui bahwa data jumlah penumpang pada BRT (Bus Rapid Transit) Trans Semarang meningkat selama tiga tahun terakhir ditengah banyaknya angkutan umum lainnya menunjukkan adanya indikasi pelayanan yang baik pada BRT Trans Semarang. Maka rumusan masalahnya adalah "bagaimana uapaya BRT Trans Semarang dalam memberikan pelayanan kepada pelanggan?”

\section{TINJAUAN PUSTAKA}

\section{Pelayanan Publik}

Pelayanan publik atau pelayanan umum sebagai segala bentuk jasa pelayanan, baik dalam bentuk barang publik maupun jasa publik yang pada prinsipnya menjadi tanggungjawab dan dilaksanakan oleh instansi pemerintah di pusat, di daerah, dan lingkungan Badan Usaha Milik Negara (BUMN) atau Badan Usaha Milik Daerah (BUMD), dalam upaya pemenuhan kebutuhan masyarakat maupun dalam rangka pelaksanaan ketentuan peraturan perundang-undangan. (Ratminto dan Winarsih (2005:5).

\section{Prinsip-prinsip Palayanan Publik}

Dalam keputusan Menteri Pendayagunaan Aparatur Negara No. 63 Tahun 2003 tentang Pedoman Umum Penyelenggaraan Pelayanan Publik, disebutkan bahwa prinsipprinsip pelayanan publik dimana adanya transaksi antara pemberi layanan dan penerima pelayanan dapat dijelaskan sebagai berikut:

1. Kesederhanaan

2. Kejelasan

3. Ketepatan waktu

4. Akurasi

5. Keamanan

6. Tanggung jawab

7. Kelengkapan sarana dan prasarana

8. Kemudahan akses

9. Kedisiplinan, kesopanan dan keramahan

10. Kenyamanan 


\section{Standar Pelayanan Publik}

Standar pelayanan publik itu adalah suatu hal yang sangat berhubungan dengan kualitas, Kualitas pelayanan pada masyarakat merupakan salah satu masalah yang mendapatkan perhatian serius oleh aparatur pemerintah. Standar Pelayanan Publik Menurut Keputusan Menteri Pendayagunaan Aparatur Negara (MenPan) Nomor 25 Tahun 2004, sekurang-kurangnya meliputi:

1. Prosedur pelayanan

2. Persyaratan pelayanan

3. Kejelasan petugas pelayanan

4. Kedisiplinan petugas pelayanan

5. Tanggung jawab petugas pelayanan

6. Kemampuan petugas pelayanan

7. Kecepatan pelayanan

8. Keadilan mendapatkan pelayanan

9. Kesopanan dan keramahan petugas

10. Kewajaran biaya pelayanan

11. Kepastian biaya pelayanan

12. Kepastian jadwal pelayanan

13. Kenyamanan lingkungan

14. Keamanan pelayanan

Sedangkan, pada keputusan Menteri Perhubungan Nomor 27 Tahun 2015 untuk mewajibkan perusahaan angkutan umum memenuhi standar pelayanan minimal, sebagai berikut :

1. Keamanan

2. Keselamatan

3. Kenyamanan

4. Keterjangkauan

5. Kesetaraan

6. Keteraturan

\section{Optimalisasi Pelayanan Publik}

Menurut kamus besar bahasa Indonesia (2005), pengoptimalan merupakan proses, cara, perbuatan mengotimalkan. Maka, dapat disimpulkan optimalisasi adalah proses ataupun cara menjadikan sempurna, menjadikan paling tinggi, atau menjadikan paling maksimal.

Menurut Sedarmayanti (2009:243) pelayanan berarti melayani suatu jasa yang dibutuhkan oleh masyarakat dalam segala bidang. Kegiatan pelayanan kepada masyarakat masyarakat merupakan salah satu tugas dan fungsi administrasi negara. 


\section{Kualitas Pelayanan}

Tjiptono (2011:59) menyatakan bahwa Kualitas Pelayanan jasa adalah tingkat keunggulan yang diharapkan dan pengendalian atas tingkat keunggulan tersebut untuk memenuhi keinginan pelanggan.

Goeth dan Davis (Tjiptono, 2012:51) menyatakan bahwa Kualitas Pelayanan jasa merupakan suatu kondisi dinamis yang berhubungan dengan produk, jasa, manusia, proses, dan lingkungan yang memenuhi atau melebihi harapan.

Dimensi Kualitas Pelayanan

Menurut Kotler (2012:284) menyebutkan lima dimensi Kualitas Pelayanan jasa yang harus dipenuhi, sebagai berikut :

1. Bukti Fisik (Tangibles)

2. Kehandalan (Reliability

3. Ketanggapan (Responsiveness)

4. Jaminan (Assurance)

5. Empati (Empathy)

\section{METODE PENELITIAN}

\section{Jenis Penelitian}

Jenis penelitian yang digunakan adalah case study atau studi kasus yaitu jenis pendekatan yang digunakan untuk menyelidiki dan memahami sebuah kejadian atau masalah yang telah terjadi dengan mengumpulkan berbagai macam informasi yang kemudian diolah untuk mendapatkan sebuah solusi agar masalah yang diungkap dapat terselesaikan. Metode ini sangat tepat untuk menganalisis kejadian tertentu di suatu tempat tertentu dan waktu yang tertentu pula.

\section{Subyek dan Obyek Penelitian}

Subjek penelitian ini adalah Pengelola BRT (Bus Rapid Transit) Trans Semarang, serta pengguna BRT (Bus Rapid Transit) Trans Semarang. Objek penelitian ini adalah faktor-faktor yang menjadi daya tarik pengguna menggunakan angkutan umum BRT Trans Semarang.

\section{Informasi Penelitian}

Dalam menetapkan informan, peneliti menggunakan teknik purposive sampling, menurut Sugiyono (2013) purposive sampling adalah teknik untuk menentukan sampel penelitian dengan beberapa pertimbangan tertentu yang bertujuan agar data yang diperoleh nantinya bisa lebih mewakilkan. Karena peneliti ingin mengetahui informasi tentang daya tarik pengguna BRT Trans Semarang, dengan demikian informan yang dipilih adalah orang yang dianggap mampu menjelaskan dan memiliki pengetahuan tentang keadaan yang terjadi pada suatu tempat atau kondisi. Pemilihan informan sebagai sumber data dalam penelitian berdasarkan atas subjek yang menjadi masalah, 
memiliki data, dan bersedia memberikan informasi lengkap dan akurat. Informan yang bertindak sebagai sumber data dan informasi harus memenuhi syarat. Dalam penelitian ini yang menjadi informan adalah pengelola BRT (Bus Rapid Transit) Trans Semarang, dan pengguna BRT (Bus Rapid Transit) Trans Semarang.

Tabel 3.1

Data Informan

\begin{tabular}{|c|l|c|c|}
\hline No. & \multicolumn{1}{|c|}{ Nama } & Kategori & Keterangan \\
\hline 1. & Bapak Mulyadi & $\begin{array}{c}\text { Pengelola Trans } \\
\text { Semarang }\end{array}$ & $\begin{array}{c}\text { Kepala Sub Bagian } \\
\text { Tata Usaha }\end{array}$ \\
\hline 2. & Femila & Pelajar & Penumpang \\
\hline 3. & Akbar & Pelajar & Penumpang \\
\hline 4. & Anugerah & Pelajar & Penumpang \\
\hline 5. & Gita & Pekerja & Penumpang \\
\hline 6. & Sausan & Pekerja & Penumpang \\
\hline
\end{tabular}

\section{Sumber : Wawancara}

\section{Metode Pengumpulan Data}

Teknik pengumpulan data dalam penelitian ini menggunakan beberapa teknik, yaitu (1) wawancara, data dikumpulkan dengan metode wawancara, yaitu dengan mewawancarai 6 orang narasumber. (2) observasi dilakukan dengan mengunjungi kantor pengelola BRT Trans Semaranng dan melakukan perjalanan dengan menggunakan transportasi BRT Trans Semarang. (3) dokumentasi lakukan dengan mengambil foto secara langsung dilapangan dan mengambil beberapa arsip dari BRT Trans Semarang.

\section{Teknik Analisi Data}

Setelah semua data dikumpulkan maka langkah selanjutnya adalah menganalisis data, sehingga data tersebut dapat ditarik kesimpulan. Teknik analisis data skripsi studi kasus terdiri dari : (1) Uji kredibilitas data, menurut Sugiyono (2014) dalam penelitian kualitatif temuan atau data dapat dinyatakan valid jika tidak ada perbedaan antara yang dilaporkan peneliti dengan yang sesungguhnya terjadi di lokasi penelitian. Uji kredibilitas data dalam penelitian ini menggunakan triangulasi sumber, yaitu menggali informasi dari berbagai narasumber dan melakukan kroscek dari jawaban jawaban narasumber. (2) narasi data, Narasi data yang diantaranya adalah melalui reduksi data, penyajian data, dan verifikasi.

\section{HASIL DAN PEMBAHASAN}

Hasil dan pembahasan menjelaskan mengenai upaya yang dilakukan BRT Trans Semarang dalam memberikan pelayanan kepada pelanggan, maka diperoleh jawaban sebagai berikut:

a. Optimalisasi Layanan 
Dalam memberikan kualitas pelayanan yang baik terhadap penumpang, Trans Semarang selalu mengoptimalkan pelayanannya seperti memberikan fasilitas yang cukup memadai, kenyamanan dan keamanan di dalam bis maupun di halte, menerapkan SOP (Standard Operating Procedure) dalam melaksanakan tugasnya agar kualitas pelayanan tercapai dengan baik. Di sisi lain pengoptimalan layanan juga bertujuan agar konsumen merasa puas dengan kualitas pelayanan yang telah diberikan oleh Trans Semarang.

Menurut kamus besar bahasa Indonesia (2005), pengoptimalan merupakan proses, cara, perbuatan mengotimalkan. Maka, dapat disimpulkan optimalisasi adalah proses ataupun cara menjadikan sempurna, menjadikan paling tinggi, atau menjadikan paling maksimal.

b. Kehandalan

Untuk memberikan kualitas pelayanan terbaik terhadap konsumen, perusahaan tak bisa terlepas dari kehandalan, baik kehandalan dari pengemudi maupun dari petugas yang bertugas dalam memberikan pelayanan, agar memberikan kepuasan tersendiri dalam menggunakan BRT (Bus Rapis Transit). Kehandalan yang di maksud dapat berupa kualitas kinerja karyawan, kehandalan dalam menggunakan skill mereka saat melayani konsumen, dan sebagainya.

Menurut Kotler (2012:284) menyebutkan lima dimensi Kualitas Pelayanan jasa yang harus dipenuhi, salah satunya adalah "Kehandalan (Reliability), yaitu kemampuan organisasi untuk memberikan pelayanan sesuai yang dijanjikan secara akurat dan terpercaya. Kinerja harus sesuai dengan harapan pelanggan yang berarti ketepatan waktu, pelayanan yang sama untuk semua pelanggan tanpa kesalahan, sikap yang simpatik, dan dengan akurasi yang tinggi."

c. Kemudahan

Trans Semarang memberikan kemudahan terkait sarana informasi, sarana aduan dan yang lainnya. Kemudahan dalam mendapatkan informasi-informasi akurat dari Trans Semarang seperti keterlambatan bis, dan lain sebagainya. Selain itu Trans Semarang juga memudahkan konsumen dalam memberikan aduan-aduan, selanjutnya aduan-aduan tersebut langsung di tindaklanjuti oleh petugas. Jadi selain memudahkan konsumen juga memudahkan petugas Trans Semarang untuk mengetahui kekurangannya dalam melakukan pelayanan, agar mudah dalam memperbaiki kekurangan-kekurangan tersebut.

Dalam proses kegiatan pelayanan terdapat prinsip pelayanan publik menurut keputusan Menteri Perhubungan nomor 63 tahun 2003 antara lain "Kemudahan akses adalah tempat dan lokasi serta sarana pelayanan yang memadai, mudah dijangkau oleh masyarakat dan dapat memanfaatkan teknologi telekomunikasi dan informatika".

d. Keselamatan

Keselamatan di dalam bis sangat di jamin oleh Trans Semarang, karena selain menjadi tanggung jawab petugas dalam bekerja, keselamatan juga 
menjadi tanggung jawab Pemerintah kota Semarang. Selain itu, untuk menjaga keselamatan penumpang Trans Semarang memberikan peraturan-peraturan agar di terapkan oleh petugas maupun penumpang saat berada di dalam bis.

Dalam Standar Pelayanan Publik menurut keputusan Menteri Perhubungan nomor 27 tahun 2015 antara lain "Menjamin keselamatan pada saat di halte maupun bis, dan menyediakan alat penyelamat di dalam bis untuk keadaan darurat".

e. Fast respons

Fast respons dalam pelayanan akan membuat pengguna merasa nyaman dalam menggunakan Trans Semarang. Seperti, menanggapi aduan-aduan yang diberikan kepada Trans Semarang, selain itu untuk informasi-informasi penting lainnya pengguna tidak perlu menunggu lama. Segala aduan, keluhan dan kekurangan dalam melakukan pelayanan langsung di tindak lanjuti oleh petugas Trans Semarang, agar semua pengguna merasa nyaman dan aman.

Fast respons termasuk di dalam dimensi daya tanggap (responsiveness). Menurut Kotler (2012:284) dimensi daya tanggap (responsiveness), yaitu suatu kemampuan untuk membuat dan memberikan pelayanan yang cepat (responsif) dan tepat kepada pelanggan, dengan penyampaian informasi yang jelas. Membiarkan konsumen menunggu tanpa adanya suatu alasan yang jelas meyebabkan persepsi negatif dalam kualitas pelayanan.

f. Petugas ramah dan tegas

Keramahan dan ketegasan petugas dalam melayani pelanggan dapat memberikan rasa nyaman dan aman kepada pelanggan nya. Hal ini juga dapat dikatakan sebagai kualitas pelayanan yang baik yang dapat mendorong minat pelanggan dalam menngunakan angkutan BRT Trans Semarang.

Dalam keputusan Menteri Pendayagunaan Aparatur Negara No. 63 Tahun 2003 tentang Pedoman Umum Penyelenggaraan Pelayanan Publik, terdapat prinsip-prinsip pelayanan publik "Kedisiplinan, kesopanan dan keramahan artinya orang-orang yang berurusan dengan proses pelayanan harus mempunyai mental dan melakukan tindakan disiplin, sopan dan ramah dalam melayaninya. Disiplin dapat berarti disiplin waktu seusai yang ditentukan, disiplin tempat, dimana harus sesuai, disiplin prosedur."

\section{KESIMPULAN DAN SARAN}

\section{Kesimpulan}

Berdasarkan hasil wawancara diatas dengan informan, para informan mengungkapkan bahwa terdapat beberapa hal yang menjadi daya tarik pengguna dalam memilih menggunakan BRT (Bus Rapid Transit) Trans Semarang adalah sebagai berikut :

Faktor yang menjadi daya tarik pengguna BRT Trans Semarang yang pertama adalah karena Trans Semarang merupakan program dari pemerintah yang tujuannya untuk mengurangi kemacetan,. Faktor selanjutnya adalah karena memiliki tarif yang 
sangat terjangkau untuk semua kalangan, apabila transit dari halte satu ke halte yang lain tidak mengeluarkan biaya lagi. Penumpang merasa nyaman dengan adanya AC (Air Conditioner) dan ruangan dalam bis yang bersih, serta terjamin keamanan nya dengan adanya tempat duduk yang terpisah antara laki-laki dan perempuan. Selain itu Trans Semarang juga menyediakan kursi prioritas untuk penumpang difabel, lansia dan ibu hamil.

Untuk memberikan kualitas pelayanan yang baik, Trans Semarang selalu mengoptimalkan kualitas pelayanan terbaik untuk pelanggan. Trans Semarang berpedoman pada 4 substansi yaitu Kehandalan, Kemudahan, Kenyamanan, Keamanan dan Keselamatan.

\section{Saran}

Berdasarkan hasil penelitian yang telah dilakukan maka saran yang akan diberikan dalam penelitian ini yaitu :

1. Pada setiap halte seharusnya terdapat masing-masing petugas yang menjaga, agar penjagaan pada setiap halte terjaga, dan konsumen yang belum paham dengan rute maupun koridor bisa bertanya langsung kepada petugas yang bersangkutan.

\section{DAFTAR PUSTAKA}

Batinggi, A dan Ahmad, Badudu. 2013. Manajemen Pelayanan Publik. Yogyakarta: Andi.

Gerson, Richard F,. 2001. Mengukur Kepuasan Pelanggan, Panduan Menciptakan Pelanggan bermutu. Jakarta: Penerbit PPM

Irawan, Handi. 2002. 10 Prinsip Kepuasan Pelanggan. Jakarta. Elex Media Komputindo

KBBI (Kamus Besar Bahasa Indonesia). (2005). Jakarta: PT (Persero) Penerbitan dan Percetakan.

Kotler, Philip dkk. (2012). Manajemen Pemasaran Perspektif Asia. Edisi Pertama. Yogyakarta : Andy

Saleh, 2010, Kualitas Pelayanan, Edisi Pertama, Universitas Indonesia, Jakarta.

Sugiyono. (2013). Metode Penelitian Kuantitatif, Kualitatif dan R\&D. Bandung: Alfabeta.CV

Sugiyono. (2014). Metode Penelitian Pendidikan Pendekatan Kuantitatif, Kualitatif, dan R\&D. Bandung: Alfabeta.

Tjiptono, Fandy. 2011. Strategi Pemasaran. Yogyakarta: Edisi Ke Empat.

Tjiptono, Fandy. 2012. Service Management Mewujudkan Layanan Prima. Yogyakarta: CV Andi Offset 